\title{
Patterns and determinants of exhaled nitric oxide trajectories in schoolchildren over a 7-year period
}

\author{
Erika Garcia (1) ${ }^{1}$, Yue Zhang², Edward B. Rappaport ${ }^{1}$, Kiros Berhane ${ }^{1}$, \\ Patrick Muchmore ${ }^{1}$, Philip E. Silkoff ${ }^{3}$, Noa Molshatzki ${ }^{1}$, Frank D. Gilliland ${ }^{1}$ and \\ Sandrah P. Eckel ${ }^{1}$
}

Affiliations: ${ }^{1}$ Dept of Preventive Medicine, Keck School of Medicine, University of Southern California, Los Angeles, CA, USA. ${ }^{2}$ Dept of Internal Medicine, University of Utah, Salt Lake City, UT, USA. ${ }^{3}$ Philadelphia, PA, USA.

Correspondence: Sandrah P. Eckel, USC Dept of Preventive Medicine, 2001 N. Soto Street, SSB 202B, MC9234, Los Angeles, CA 90089, USA. E-mail: eckeldusc.edu

@ERSpublications

Longitudinal $F_{\mathrm{ENO}_{50}}$ trajectories in healthy children aged 8-16 years displayed a similar upward trend in males and females until age 11.5, after which males had higher $F_{\mathrm{ENO}_{50}}$. Males with higher starting BMI percentile had attenuated $F_{\mathrm{ENO}_{50}}$ slopes with age. https://bit.ly/2UMb8mI

Cite this article as: Garcia E, Zhang Y, Rappaport EB, et al. Patterns and determinants of exhaled nitric oxide trajectories in schoolchildren over a 7-year period. Eur Respir J 2020; 56: 2000011 [https://doi.org/ 10.1183/13993003.00011-2020].

ABSTRACT Fractional exhaled nitric oxide $\left(F_{\mathrm{ENO}_{50}}\right)$, a marker of allergic airway inflammation, is used in respiratory research and asthma clinical care; however, its trajectory with increasing age during childhood has not been well characterised. We examined $F_{\mathrm{ENO}_{50}}$ longitudinally during a period of important somatic growth to describe trajectories across childhood and adolescence in healthy participants and evaluate clinical factors as potential determinants of trajectories.

$F_{\mathrm{ENO}_{50}}$ was collected at six visits over 8 years in a population-based cohort of 1791 schoolchildren without asthma (median age at entry 8.4 years). Smooth sex-specific $F_{\mathrm{ENO}_{50}}$ trajectories were estimated using generalised additive mixed models, with participant-level random effects. We evaluated whether sexspecific trajectories were influenced by race/ethnicity, body mass index (BMI) percentile, allergic rhinitis or puberty.

Different $F_{\mathrm{ENO}_{50}}$ patterns were observed by sex in later childhood and several factors were associated with either $F_{\mathrm{ENO}_{50}}$ level or change in $F_{\mathrm{ENO}_{50}}$ as participants aged. $F_{\mathrm{ENO}_{50}}$-age trajectories were similar by sex until age $\sim 11.5$ years, after which males had greater $F_{\mathrm{ENO}_{50}}$ change than females. This divergence in $F_{\mathrm{ENO}_{50}}$-age trajectories coincides with puberty. Males with higher starting BMI percentile had attenuated $F_{\mathrm{ENO}_{50}}$-age slopes. Among males, $F_{\mathrm{ENO}_{50}}$ levels were lower in non-Hispanic white subjects. Among both sexes, participants with rhinitis had higher $F_{\mathrm{ENO}_{50}} . F_{\mathrm{ENO}_{50}}$ levels within individuals tracked over time; however, there was considerable variation in $F_{\mathrm{ENO}_{50}}$ patterns across participants.

$F_{\mathrm{ENO}_{50}}$ trajectories from longitudinal data provide evidence of sex differences coinciding with puberty, suggesting potential hormone link. Improved understanding of determinants of $F_{\mathrm{ENO}_{50}}$ trajectories is needed to realise the potential for using individualised predicted $F_{\mathrm{ENO}_{50}}$ trajectories. 


\section{Introduction}

There is increasing evidence of the utility of fractional exhaled nitric oxide $\left(F_{\mathrm{ENO}_{50}}\right)$, a noninvasive biomarker of allergic airway inflammation, for research, patient management of asthma treatment and in providing supporting evidence for asthma diagnosis [1-4]. Examining trends with age in $F_{\mathrm{ENO}_{50}}$ among healthy children during this critical period of growth as well as the impact of clinical factors such as sex, race/ethnicity and allergic disease may enhance the utility of $F_{\mathrm{ENO}_{50}}$ in clinical and research settings.

Prior studies of the distribution and determinants of $F_{\mathrm{ENO}_{50}}$ in healthy paediatric populations were based on single cross-sectional measurements among children across a range of ages [5-11], which may have missed important patterns in $F_{\mathrm{ENO}_{50}}$ change as children grow. Serial measurements within the same set of children as they age are likely to be more informative for understanding trajectory of $F_{\mathrm{ENO}_{50}}$ across childhood and adolescence as well as potential determinants of this evolution. Furthermore, during childhood and adolescence there is an important epidemiological shift in the rates of allergic diseases, including asthma and allergic rhinitis, with higher rates among males during childhood, followed by higher rates in adolescence among females, a reversal that may be puberty related [12-14]. A better understanding of $F_{\mathrm{ENO}_{50}}$ trajectories coinciding with the timing of this transition is needed for improved use of $F_{\mathrm{ENO}_{50}}$ in research and clinical medicine.

The aim of this study was to examine $F_{\mathrm{ENO}_{50}}$ trajectories across childhood and adolescence in a unique data resource of healthy children from the Southern California Children's Health Study (CHS) with serial $F_{\mathrm{ENO}_{50}}$ measurements during a period of rapid somatic growth, ages 8-16 years. We investigate sex-specific $F_{\mathrm{ENO}_{50}}$ trajectories as a function of age and height, and evaluate potential determinants of $F_{\mathrm{ENO}_{50}}$ trajectories including race/ethnicity, body mass index (BMI), allergic rhinitis and puberty.

\section{Material and methods \\ Study design and study population}

This study was performed within a cohort of the population-based CHS, described in detail previously [15]. Briefly, in 2002-2003, a prospective cohort of children primarily aged 6-7 years was enrolled from kindergarten and first grade public school classrooms from 13 communities. Follow-up for $F_{\mathrm{ENO}_{50}}$ began in study year 3. Ethical approval of the protocol was obtained from the University of Southern California institutional review board (approval \# HS-13-00150, continuing review date April 17, 2019). Informed consent was obtained from a parent or guardian at first and follow-up visits through 2007-2008, and informed assent was obtained from each child at visits after 2008.

Because the study aim was to examine $F_{\mathrm{ENO}_{50}}$ trajectories in healthy children, we excluded participants with any history of asthma based on all study questionnaire data $(\mathrm{n}=618)$. We sequentially excluded $F_{\mathrm{ENO}_{50}}$ measurements conducted when height was not recorded (29 observations), or the participant had reported respiratory infection within the past 3 days (389 observations) or the participant had reported personal smoking within the last month (56 observations). These last eligibility criteria excluded that year's $F_{\mathrm{ENO}_{50}}$ measurements and not the participants themselves, who could contribute $F_{\mathrm{ENO}_{50}}$ measurements in years when they met eligibility criteria for $F_{\mathrm{ENO}_{50}}$ measurements. The final study population consisted of 1791 healthy children with $7185 F_{\mathrm{ENO}_{50}}$ measurements.

\section{Measurement of exhaled nitric oxide}

$F_{\mathrm{ENO}_{50}}$ assessment in the CHS has been described in detail previously [16-18]. Briefly, $F_{\mathrm{ENO}_{50}}$ was collected at schools using an offline breath collection technique in years 3-4 at $100 \mathrm{~mL} \cdot \mathrm{s}^{-1}$ flow using Sievers sampling kits and analysed using a Sievers (Boulder, CO, USA) model 280i NO analyser, and online using ECO MEDICS CLD-88-SP instruments (with DeNOx; Duernten, Switzerland) at $50 \mathrm{~mL} \cdot \mathrm{s}^{-1} \mathrm{flow}$ during years 5, 6, 8 and 10, following manufacturers' instructions and professional societies' guidelines $[4,19]$

TABLE 1 Study design information including type and number of fractional exhaled nitric oxide $\left(F_{\text {ENO }_{50}}\right)$ measurements and average participant age over the study period

\begin{tabular}{|c|c|c|c|c|c|c|c|c|}
\hline & \multicolumn{8}{|c|}{ Study year } \\
\hline & 1 & 2 & $3^{\#}$ & 4 & 5 & 6 & 8 & 10 \\
\hline Calendar years & $2002-2003$ & 2003-2004 & 2004-2005 & $2005-2006$ & $2006-2007$ & $2007-2008$ & $2009-2010$ & 2011-2012 \\
\hline$F_{\mathrm{ENO}_{50}}$ measure type & \multicolumn{2}{|c|}{ None } & \multicolumn{2}{|c|}{ Offline } & \multicolumn{4}{|c|}{ Online } \\
\hline Participants with $F_{\mathrm{ENO}_{50}}$ data $\mathrm{n}$ & & & 1429 & 1498 & 1364 & 1100 & 938 & 856 \\
\hline Mean age years & & & 8.4 & 9.3 & 10.3 & 11.4 & 13.5 & 15.3 \\
\hline
\end{tabular}


(table 1; additional details in supplementary material). Offline $F_{\mathrm{ENO}_{50}}$ values were converted to online values at $50 \mathrm{~mL} \cdot \mathrm{s}^{-1}$ using a prediction model developed internally $\left(R^{2}=0.94\right)$ from a pilot study including concurrent offline and online measurements among 362 schoolchildren in 2006-2007 [17]. Prediction model inputs included offline $F_{\mathrm{ENO}_{50}}$, ambient nitric oxide (NO) and lag time before analysis [17]. Model-predicted online $F_{\mathrm{ENO}_{50}}$ estimates produced results similar to observed online $F_{\mathrm{ENO}_{50}}$ measures in analysis of school and age differences [17].

\section{Covariate assessment}

Parents/guardians completed written questionnaires at first and follow-up visits (children responded beginning year 8 when they were aged $13.5 \pm 0.63$ years, providing information on child's sex, race/ ethnicity, date of birth, allergic rhinitis and history of doctor-diagnosed asthma. Ever-reported allergic rhinitis at year 3 was defined based on responses to the questions "has your child ever/in the past 12 months had a problem with sneezing or a runny or blocked nose, when he/she did not have a cold or the 'flu?" and "in the past 12 months, has this nose problem been accompanied by itchy-watery eyes?" We categorised a positive response to both questions as "allergic rhinitis". Children were classified as having asthma if it was reported on any questionnaire that a doctor had "ever diagnosed this child as having asthma". Reported respiratory infection within the past 3 days was based on questionnaire data from parents (through year 6) or participants (years 8 and 10). Starting year 6, children were asked about personal smoking (cigarettes or anything else) $[15,18]$. Height and weight measurements were used to calculate age- and sex-specific BMI percentiles (BMI\%) from the Centers for Disease Control and Prevention growth charts [20]. Height velocity was calculated as the difference in height divided by the difference in age between consecutive annual study visits. Age at peak height velocity (a proxy for puberty [21]) was then determined and subsequently categorised as "early" or "late" based on sex-specific median.

\section{Statistical analysis}

$F_{\mathrm{ENO}_{50}}$ values are right-skewed. Therefore, unless otherwise specified, we performed analyses with natural $\log$-transformed $F_{\mathrm{ENO}_{50}}\left(\log F_{\mathrm{ENO}_{50}}\right)$, with results presented using back-transformed values. Analyses were stratified by sex a priori, based on reported differences in $F_{\mathrm{ENO}_{50}}$ between male and female children [5].

Descriptive analyses present study population characteristics and describe sex-specific associations of these characteristics with year $3 F_{\mathrm{ENO}_{50}}$ in the subset of $\mathrm{n}=1429$ participants with available $F_{\mathrm{ENO}_{50}}$ and with percentage change in $F_{\mathrm{ENO}_{50}}$ from year 3 (median (interquartile range (IQR)) age 8.4 (7.9-8.9) years) to year 10 (median (IQR) age 15.3 (14.7-15.8) years) in the subset of $\mathrm{n}=681$ children with $F_{\mathrm{ENO}_{50}}$ measured in both years. Percentage change relates the geometric mean of $F_{\mathrm{ENO}_{50}}$ at year 10 to the geometric mean of $F_{\mathrm{ENO}_{50}}$ at year 3 (i.e. exponentiated mean difference in $\log F_{\mathrm{ENO}_{50}}$ from year 3 to 10 ). We evaluated statistical significance of differences between categorical covariates for year $3 F_{\mathrm{ENO}_{50}}$ using one-way ANOVA and for years 3-10 $F_{\mathrm{ENO}_{50}}$ percentage change using a non-parametric Kruskal-Wallis test. To quantify the correlation of repeated, longitudinal measurements of $\log F_{\mathrm{ENO}_{50}}$ in participants over the 8 -year period, we calculated intraclass correlation coefficients (ICC).

Sex-specific $F_{\mathrm{ENO}_{50}}$ trajectories as functions of age and/or height were modelled by fitting generalised additive mixed models [22, 23], with a participant-level random intercept and random slope on age (or on height for height-only model), to all available data on the 1791 participants using the R package "mgcv" [23]. Smooth functions of only height or only age were fitted using a penalised regression spline [23]. A joint smooth function of age and height was fitted using a penalised tensor product smooth [23]. Next, using data on 1717 participants with complete year $3 \mathrm{BMI} \%$, we evaluated whether sex-specific age trajectories were influenced by 1) year 3 BMI\%; 2) race/ethnicity (Hispanic, White/non-Hispanic, other (includes missing)); or 3) year 3 ever-reported allergic rhinitis (yes, no, missing), using parameterisations that allowed for quantification of age interactions (supplementary material). Based on statistical significance in bivariate analyses, final models for $F_{\mathrm{ENO}_{50}}$-age trajectories were then developed. Lastly, we stratified final models by dichotomised (early or late) age at peak height velocity as a proxy for puberty. Sensitivity analysis included analyses 1) with height instead of age trajectories; 2) with time-varying BMI\% collected over follow-up instead of year $3 \mathrm{BMI} \%$; 3) restricted to 1062 children who never reported allergic rhinitis through year 10 ; 4) restricted to 1526 children who never reported wheeze or whistling in the chest through year 10 ; and 5) restricted to online $F_{\mathrm{ENO}_{50}}$ measurements only. All statistical analyses were performed using R 3.5.1 [24].

\section{Results}

Participants' mean \pm SD age was $8.4 \pm 0.65$ years in study year 3 , the initial year of $F_{\mathrm{ENO}_{50}}$ follow-up. In year 3 $(\mathrm{n}=1429)$, geometric mean $F_{\mathrm{ENO}_{50}}$ was $10.6 \mathrm{ppb}$ (geometric standard deviation $1.84 \mathrm{ppb}$ ), with no difference by sex $(\mathrm{p}=0.90)$. Median (IQR) follow-up time from first to last $F_{\mathrm{ENO}_{50}}$ measurement was 5.2 (2.0-6.8) years and $46.6 \%$ of participants had five or six $F_{\mathrm{ENO}_{50}}$ measurements (mean 4.0; supplementary 
table E1). Supplementary figure E1 shows example trajectories. The ICC was 0.57 for males and 0.59 for females, indicating moderately strong within-participant correlation of $F_{\mathrm{ENO}_{50}} . F_{\mathrm{ENO}_{50}}$ generally increased from year 3 to 10. Percentage change in $F_{\mathrm{ENO}_{50}}$ from year 3 to 10 in the $\mathrm{n}=681$ children with available data was higher in males than females $(53.2 \%$ versus $14.4 \%$, respectively; $\mathrm{p}<0.001)$. There were no statistically significant differences in covariate distributions between participants with and without year 10 data (supplementary table E1).

In descriptive analyses, determinants of year $3 F_{\mathrm{ENO}_{50}}$ were different from determinants of $F_{\mathrm{ENO}_{50}}$ change from years 3 to 10 , as shown in tables 2 (males) and 3 (females). In year $3, F_{\mathrm{ENO}_{50}}$ was statistically significantly different by race/ethnicity for males and by age and allergic rhinitis for females. From years 3 to 10 , there was modest evidence for differences in percentage change in $F_{\mathrm{ENO}_{50}}$ by year $3 \mathrm{BMI} \%$ in males $(\mathrm{p}=0.07)$, with an attenuated increase in $F_{\mathrm{ENO}_{50}}$ for those with higher year $3 \mathrm{BMI} \%$. Among females, percentage change in $F_{\mathrm{ENO}_{50}}$ differed by age and height in year 3, with larger $F_{\mathrm{ENO}_{50}}$ change among those younger or shorter in year 3 .

Estimates of population-averaged sex-specific trajectories of $F_{\mathrm{ENO}_{50}}$ by age and/or height $(\mathrm{n}=1791)$ are displayed in figure 1 and summarised in supplementary table E2. As a function of age, estimated geometric mean $F_{\mathrm{ENO}_{50}}$ at age 8 years was similar by sex (10.6 and $10.7 \mathrm{ppb}$ for males and females, respectively) and the nonlinear $F_{\mathrm{ENO}_{50}}$ trajectory was similar by sex through age $\sim 11.5$ years. After age 11.5 years, males tended to have a larger increase in $F_{\mathrm{ENO}_{50}}$ than females. By age 15 years, predicted geometric mean $F_{\mathrm{ENO}_{50}}$ for an average male was 16.5 (95\% CI 15.4-17.6) ppb and for an average female 12.6 (11.913.4) ppb. This translates to an increase from age 8 to 15 years of $54.9 \%$ (44.8-65.8\%) for the average male and $17.8 \%(11.0-25.0 \%)$ for the average female. As a function of height, $F_{\mathrm{ENO}_{50}}$ trajectory for an average child was nearly linear for males and nonlinear for females, with a shallower slope. When considering

TABLE 2 For males, participant characteristics at year 3 and associations with fractional exhaled nitric oxide $\left(F_{\mathrm{ENO}_{50}}\right)$ or percentage change in $F_{\mathrm{ENO}_{50}}$ over $\sim 7$ years

Year $3 F_{\mathrm{ENO}_{50}}$

Subjects Geometric mean p-value ${ }^{\#}$

Subjects 672

Age years

$$
7
$$

8

9

10

Height $\mathrm{cm}$

$\leqslant 125$

125-130

130-135

$>135$

BMI percentile

0-15

$15-85$

85-95

$>95$

Race/ethnicity

Hispanic

White/non-Hispanic

Black

Asian

Other

Missing

Ever-reported allergic rhinitis No

Yes

Missing
672

$48(7)$

313 (47)

$276(41)$

35 (5)

$129(19)$

$168(25)$

205 (31)

$170(25)$

$41(6)$

359 (53)

122 (18)

150 (22)

386 (57)

226 (34)

12 (2)

27 (4)

19 (3)

2 (0.3)

380 (57)

193 (29)

99 (15)
Percentage change in $F_{\mathrm{ENO}_{50}}$ years $3-10$

Subjects Estimate p-value ${ }^{\pi}$

9.2

10.3

11.0

11.6

9.9

10.9

10.1

11.4

10.4

10.7

10.6

10.4

11.0

9.5

10.4

18.1

8.0

17.1

10.2

11.5

10.3
318

0.178

25 (8)

144 (45)

133 (42)

16 (5)

0.140

50 (16)

73 (23)

$114(36)$

81 (25)

0.957

22 (7)

169 (53)

61 (19)

66 (21)

$<0.001$

177 (56)

115 (36)

4 (1)

11 (3)

10 (3)

$1(0.3)$

0.109

180 (57)

$94(30)$

44 (14)
60.4

52.1

56.5

26.8

56.7

46.1

60.7

47.2

0.067

45.6

68.2

44.5

29.3

62.9

48.2

67.0

28.4

72.2

$-35.4$

51.2

57.7

51.5

Data are presented as $\mathrm{n}$ or $\mathrm{n}(\%)$, unless otherwise stated. \#: ANOVA F-test lexcluding missing categories, if applicable); ": Kruskal-Wallis test, a nonparametric alternative to ANOVA (excluding missing categories, if applicable). 
TABLE 3 For females, participant characteristics at year 3 and associations with fractional exhaled nitric oxide $\left(F_{\mathrm{ENO}_{50}}\right)$ or percentage change in $F_{\mathrm{ENO}_{50}}$ over $\sim 7$ years

\begin{tabular}{|c|c|c|c|c|c|c|}
\hline & \multicolumn{3}{|c|}{ Year $3 F_{\mathrm{ENO}_{50}}$} & \multicolumn{3}{|c|}{$\begin{array}{c}\text { Percentage change in } F_{\mathrm{ENO}_{50}} \\
\text { years } 3-10\end{array}$} \\
\hline & Subjects & Geometric mean & p-value ${ }^{\#}$ & Subjects & Estimate & p-value \\
\hline Subjects & 757 & & & 363 & & \\
\hline Age years & & & 0.001 & & & 0.069 \\
\hline 7 & $65(9)$ & 8.7 & & 33 (9) & 34.5 & \\
\hline 8 & $381(50)$ & 10.3 & & 179 (49) & 18.6 & \\
\hline 9 & $288(38)$ & 11.7 & & 136 (37) & 4.3 & \\
\hline 10 & $23(3)$ & 10.0 & & $15(4)$ & 22.1 & \\
\hline Height cm & & & 0.166 & & & 0.040 \\
\hline$\leqslant 125$ & 202 (27) & 10.2 & & 92 (25) & 31.4 & \\
\hline $125-130$ & 143 (19) & 11.6 & & $68(19)$ & 2.1 & \\
\hline $130-135$ & $236(31)$ & 10.3 & & $117(32)$ & 16.4 & \\
\hline$>135$ & $176(23)$ & 10.8 & & $86(24)$ & 5.6 & \\
\hline BMI percentile & & & 0.962 & & & 0.445 \\
\hline $0-15$ & $58(8)$ & 10.5 & & $21(6)$ & 30.3 & \\
\hline $15-85$ & $452(60)$ & 10.5 & & $223(61)$ & 16.1 & \\
\hline $85-95$ & $127(17)$ & 10.8 & & $64(18)$ & 13.5 & \\
\hline$>95$ & $120(16)$ & 10.8 & & 55 (15) & 3.8 & \\
\hline Race/ethnicity & & & 0.131 & & & 0.394 \\
\hline Hispanic & 449 (59) & 11.1 & & $203(56)$ & 14.2 & \\
\hline White/non-Hispanic & $219(29)$ & 9.8 & & $114(31)$ & 11.4 & \\
\hline Black & $14(2)$ & 13.0 & & $6(2)$ & 8.0 & \\
\hline Asian & $31(4)$ & 10.6 & & $14(4)$ & 44.9 & \\
\hline Other & $41(5)$ & 9.6 & & $25(7)$ & 24.9 & \\
\hline Missing & $3(0.4)$ & 10.7 & & $1(0.3)$ & 102.2 & \\
\hline Ever-reported allergic rhinitis & & & 0.022 & & & 0.122 \\
\hline No & $467(62)$ & 10.2 & & $238(66)$ & 14.7 & \\
\hline Yes & $206(27)$ & 11.7 & & $84(23)$ & 20.6 & \\
\hline Missing & $84(11)$ & 10.7 & & $41(11)$ & 1.4 & \\
\hline
\end{tabular}

Data are presented as $\mathrm{n}$ or $\mathrm{n}(\%)$, unless otherwise stated. ${ }^{\#}$ : ANOVA F-test lexcluding missing categories, if applicable); ${ }^{\Uparrow}$ : Kruskal-Wallis test, a nonparametric alternative to ANOVA (excluding missing categories, if applicable).

joint smooths of age and height, there was evidence of an interaction (figure $1 \mathrm{c}$ and $\mathrm{d}$, supplementary table E2). For example, for females (figure 1d) the positive association between age and $F_{\mathrm{ENO}_{50}}$ was attenuated for taller younger females (approximate height $>140 \mathrm{~cm}$, age $<13$ years) and negative for taller older females (approximate height $>140 \mathrm{~cm}$, age $\geqslant 13$ years).

There was considerable between-participant heterogeneity (i.e. nonuniformity), as shown in the participant-specific predicted trajectories (figure 2). To put estimated random intercept standard deviations into context (males 0.50 , females $0.47\left(\log F_{\mathrm{ENO}_{50}}\right.$ scale)), estimated average $F_{\mathrm{ENO}_{50}}$ for males at age 8 years was $10.6 \mathrm{ppb}$, but with a $95 \%$ confidence interval that ranged from $4.0 \mathrm{ppb}$ to $28.2 \mathrm{ppb}$ (exp $(2.36 \pm 1.96 \times 0.50))$. Subsequent "tracking" of participant-specific predicted trajectories is apparent in figure 2, with participants with high (or low) $F_{\mathrm{ENO}_{50}}$ at start of follow-up generally having high (or low) $F_{\mathrm{ENO}_{50}}$ through end of follow-up. In addition, there was considerable heterogeneity in the random slopes on age (SD males 0.051, females 0.052). For context, linear mixed effects models assuming a linear (rather than smooth) trajectory of $\log F_{\mathrm{ENO}_{50}}$ in age had population average slopes on age of 0.061 for males and 0.022 for females.

The estimated sex-specific age trajectories of $F_{\mathrm{ENO}_{50}}$ by categories of sex, race/ethnicity and allergic rhinitis, and year $3 \mathrm{BMI} \%(\mathrm{n}=1717)$ are displayed in figure 3 and summarised in table 4 and supplementary table E3. The only covariate that significantly modified the average $F_{\mathrm{ENO}_{50}}$ age trajectory (i.e. $F_{\mathrm{ENO}_{50}}$ change from age 8 to 16 years) was year $3 \mathrm{BMI} \%$ in males. Males with higher year $3 \mathrm{BMI} \%$ had a lower rate of $F_{\mathrm{ENO}_{50}}$ increase than males with lower BMI (interaction $\mathrm{p}=0.009$ ) as demonstrated in figure 3 and supplementary figure E3c-d. Year 3 allergic rhinitis in both sexes and race/ethnicity in males shifted the intercept of, but did not modify, $F_{\mathrm{ENO}_{50}}$-age trajectories. At any given age, children reporting allergic rhinitis ever in year 3 had higher $F_{\mathrm{ENO}_{50}}(\mathrm{p}<0.001)$ and $F_{\mathrm{ENO}_{50}}$ was higher for males in the "other" race/ ethnicity group (composed of Black, Asian, other and missing) than in the Hispanic group ( $\mathrm{p}=0.02)$. 

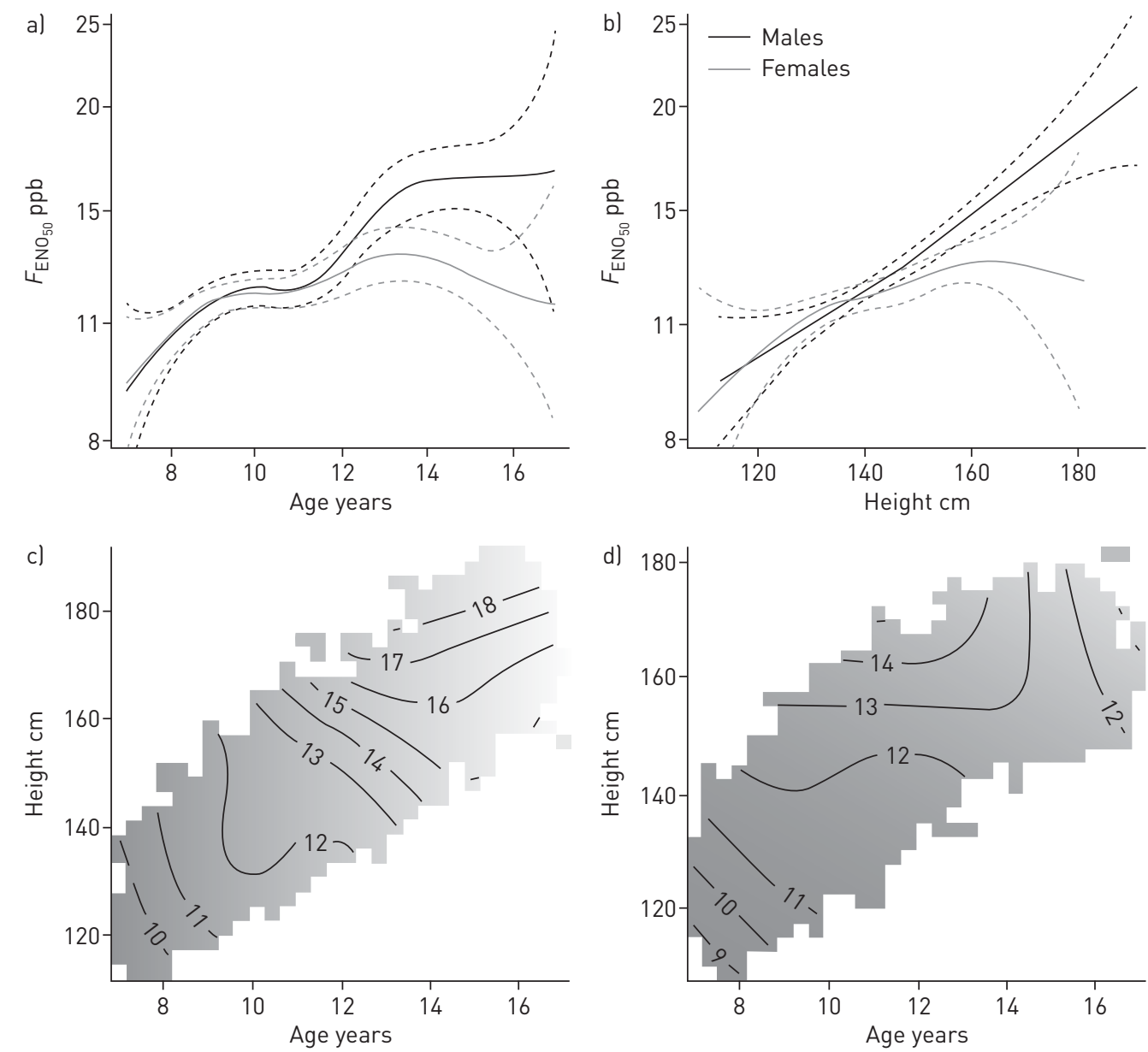

FIGURE 1 Population-averaged sex-specific trajectories $(95 \% \mathrm{Cl})$ of fractional exhaled nitric oxide $\left(F_{\mathrm{ENO}_{50}}\right)$ ( $\mathrm{n}=851$ males, $\mathrm{n}=940$ females) and modelled as a) a smooth function of age only, b) a smooth function of height only, or a joint smooth of age and height for $c$ ) males or d) females. In panels (c-d), the contour line labels refer to predicted geometric mean $F_{\mathrm{ENO}_{50}}$ in $\mathrm{ppb}$. Analyses performed using $\log F_{\mathrm{ENO}_{50}}$ with results here presented using back-transformed values on an axis scaled using natural log.
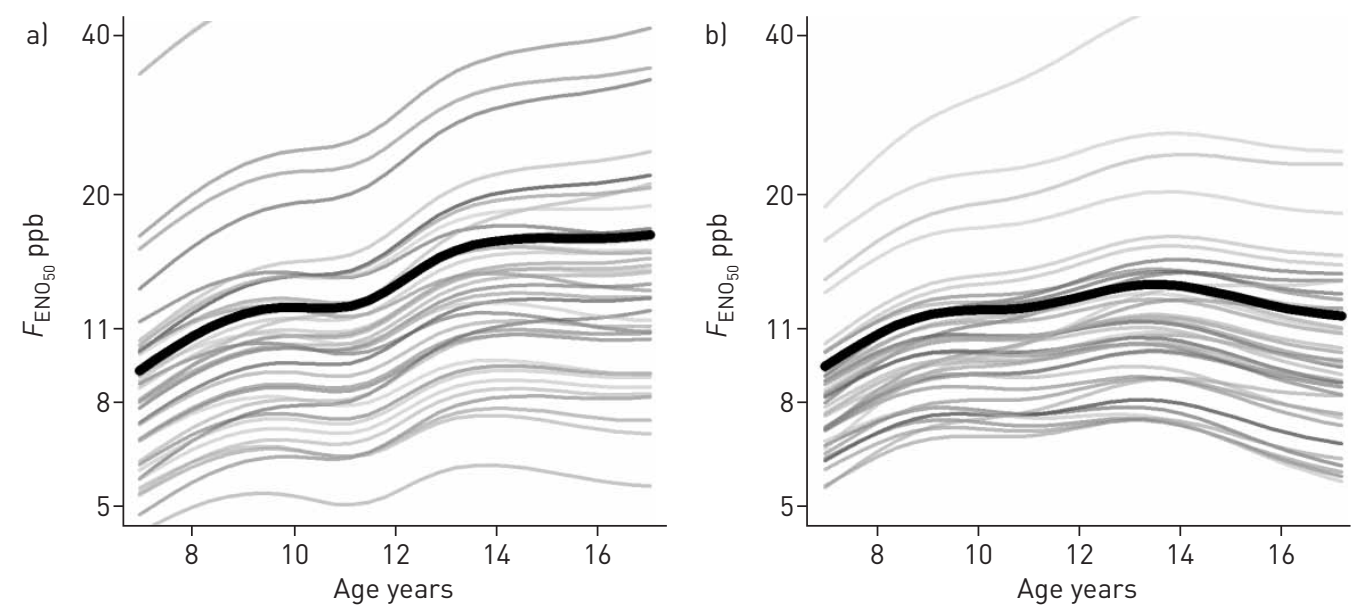

FIGURE 2 Participant-specific predicted trajectories of fractional exhaled nitric oxide $\left(F_{\mathrm{ENO}_{50}}\right)$, modelled as a smooth function of age, for a) 40 randomly selected males and b) 40 randomly selected females. Analyses performed using $\log F_{\mathrm{ENO}_{50}}$ with results here presented using back-transformed values on an axis scaled using natural log. The population average predictions (identical to figure 1a) are plotted with a heavy black line. 

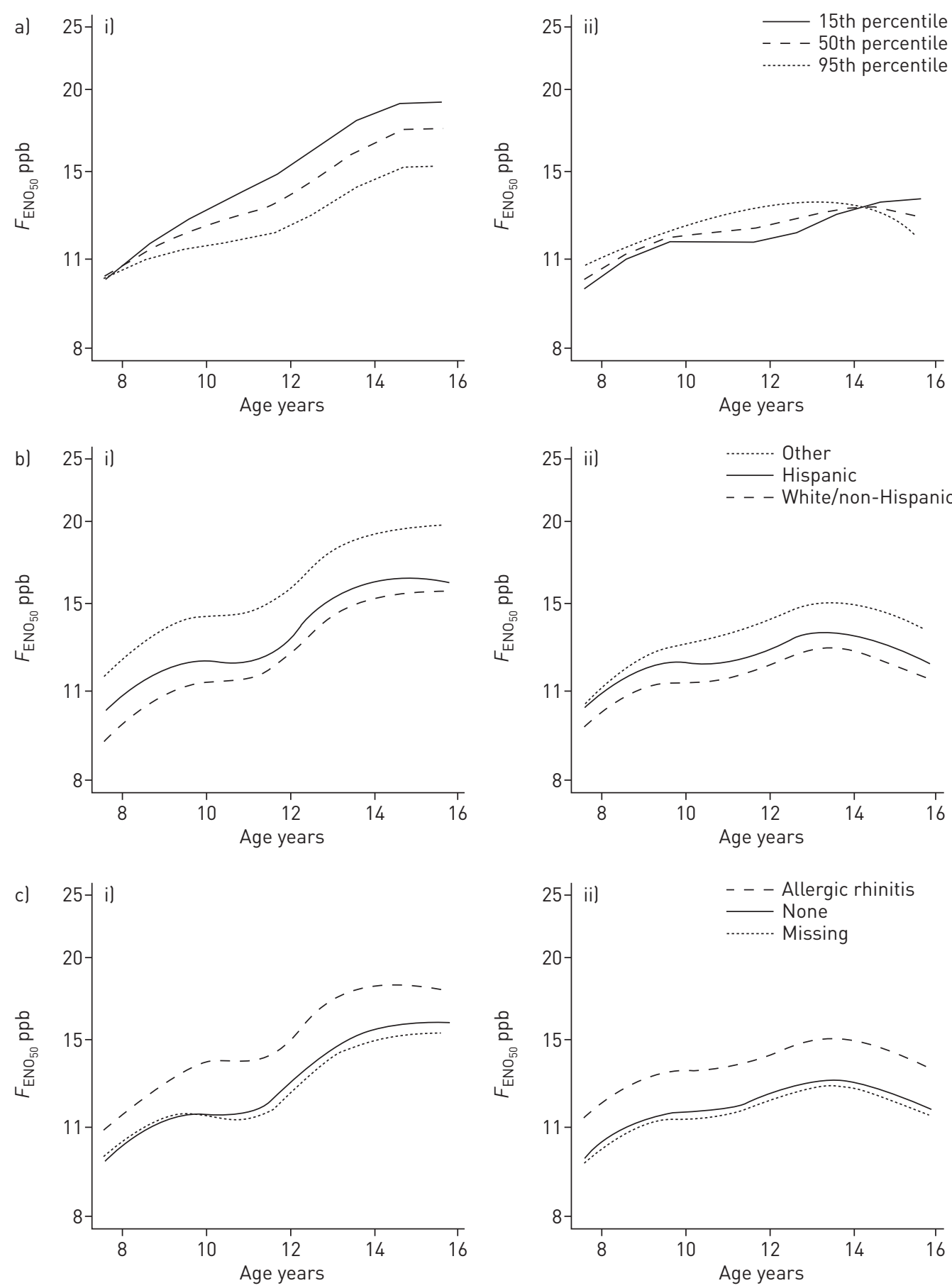

FIGURE 3 Modelled sex-specific trajectory of fractional exhaled nitric oxide $\left(F_{\mathrm{ENO}_{5}}\right)$ as a) a joint smooth of age and year 3 body mass index percentile or b) as smooths of age that vary by race/ethnicity or $c$ ) ever-reported allergic rhinitis in year 3 in i) males $(n=809)$ and ii) females $(n=908)$. Analyses performed using $\log F_{\mathrm{ENO}_{50}}$ with results here presented using back-transformed values on an axis scaled using natural log.

Finally, we estimated sex-specific models including the joint smooth function of age and year 3 BMI\% and main effects of race/ethnicity and year 3 allergic rhinitis. Associations were similar to those reported in models including one covariate at a time (table 4). Predictions for participants with selected covariate values are provided in supplementary table $\mathrm{E} 4$ to demonstrate the range of $F_{\mathrm{ENO}_{50}}$ values and rates of change over time. Despite statistically significant evidence for covariate associations with $F_{\mathrm{ENO}_{50}}$ levels and trajectories, inclusion of the three covariates in the final model did not considerably reduce the standard deviation of the random intercept (males 0.49, females 0.47) or random slope (males 0.049, females 0.052), nor did it improve model fit based on bayesian information criterion (supplementary table E3). 
TABLE 4 Summary of fitted generalised additive mixed models that model longitudinal log fractional exhaled nitric oxide $\left(\log F_{\mathrm{ENO}_{50}}\right)$ trajectories as smooth functions of time-varying age and a time-constant covariate plus a participant-level random intercept and random slope on age

\begin{tabular}{|c|c|c|c|c|c|c|}
\hline & \multicolumn{3}{|c|}{ Males } & \multicolumn{3}{|c|}{ Females } \\
\hline & $\begin{array}{l}\text { Regression } \\
\text { coefficient }\end{array}$ & EDF $^{\pi}$ & p-value & $\begin{array}{l}\text { Regression } \\
\text { coefficient }\end{array}$ & EDF $^{\top 1}$ & p-value \\
\hline Subjects n & & 809 & & & 908 & \\
\hline $\begin{array}{l}\text { Age only } \\
\text { slage) }\end{array}$ & & 5.6 & $<0.0001$ & & 5.1 & $<0.0001$ \\
\hline $\begin{array}{c}\text { Age and year } 3 \text { BMI\% } \\
\text { telage, BMI\%) }\end{array}$ & & 8.4 & $<0.0001$ & & 7.6 & $<0.0001$ \\
\hline $\begin{array}{l}\text { tilage) } \\
\text { ti(BMI\%) } \\
\text { tilage, BMI\%) }\end{array}$ & & $\begin{array}{l}3.8 \\
1.0 \\
1.7\end{array}$ & $\begin{array}{c}<0.0001 \\
0.02 \\
0.009\end{array}$ & & $\begin{array}{l}3.6 \\
1.0 \\
2.7\end{array}$ & $\begin{array}{c}<0.0001 \\
0.43 \\
0.07\end{array}$ \\
\hline $\begin{array}{l}\text { Age and race/ethnicity } \\
\text { Intercept } \\
\text { White/non-Hispanic } \\
\text { Other } \\
\text { slage) } \\
\text { slage:Hispanic) } \\
\text { slage:White/non-Hispl } \\
\text { slage:Other) }\end{array}$ & $\begin{array}{c}2.55 \\
-0.07 \\
0.16\end{array}$ & $\begin{array}{l}5.4 \\
1.6 \\
<0.1 \\
<0.1\end{array}$ & $\begin{array}{c}<0.0001 \\
0.11 \\
0.02 \\
<0.0001 \\
0.13 \\
0.31 \\
0.70\end{array}$ & $\begin{array}{c}2.49 \\
-0.06 \\
0.07\end{array}$ & $\begin{array}{c}5.1 \\
0.5 \\
<0.1 \\
1.2\end{array}$ & $\begin{array}{c}<0.0001 \\
0.13 \\
0.21 \\
<0.0001 \\
0.23 \\
0.51 \\
0.11\end{array}$ \\
\hline $\begin{array}{l}\text { Age and ever-reported } \\
\text { allergic rhinitis at year } \\
\text { Intercept } \\
\text { Allergic rhinitis } \\
\text { Missing } \\
\text { slage) } \\
\text { slage:None) } \\
\text { slage:AllergicRhinitis) } \\
\text { slage:Missing) }\end{array}$ & $\begin{array}{c}2.50 \\
0.15 \\
-0.01\end{array}$ & $\begin{array}{c}5.5 \\
<0.1 \\
2.7 \\
1.0\end{array}$ & $\begin{array}{c}<0.0001 \\
0.001 \\
0.83 \\
<0.0001 \\
0.40 \\
0.07 \\
0.16\end{array}$ & $\begin{array}{c}2.45 \\
0.14 \\
-0.02\end{array}$ & $\begin{array}{l}5.0 \\
<0.1 \\
<0.1 \\
<0.1\end{array}$ & $\begin{array}{c}<0.0001 \\
0.0005 \\
0.70 \\
<0.0001 \\
0.62 \\
0.51 \\
0.74\end{array}$ \\
\hline $\begin{array}{l}\text { Full model } \\
\text { Intercept } \\
\text { White/non-Hispanic } \\
\text { Other } \\
\text { Allergic rhinitis } \\
\text { Missing } \\
\text { telage, BMI\%) }\end{array}$ & $\begin{array}{c}2.52 \\
-0.10 \\
0.13 \\
0.15 \\
-0.02\end{array}$ & 8.4 & $\begin{array}{c}<0.0001 \\
0.02 \\
0.07 \\
0.001 \\
0.79 \\
<0.0001\end{array}$ & $\begin{array}{c}2.46 \\
-0.07 \\
0.05 \\
0.15 \\
-0.03\end{array}$ & 7.6 & $\begin{array}{c}<0.0001 \\
0.09 \\
0.35 \\
0.0004 \\
0.56 \\
<0.0001\end{array}$ \\
\hline $\begin{array}{l}\text { Intercept } \\
\text { White/non-Hispanic } \\
\text { Other } \\
\text { Allergic rhinitis } \\
\text { Missing } \\
\text { tilage) } \\
\text { ti(BMI\%) } \\
\text { tilage, BMI\%) }\end{array}$ & $\begin{array}{c}2.52 \\
-0.10 \\
0.13 \\
0.15 \\
-0.02\end{array}$ & $\begin{array}{l}3.8 \\
1.0 \\
1.5\end{array}$ & $\begin{array}{c}<0.0001 \\
0.02 \\
0.07 \\
0.001 \\
0.79 \\
<0.0001 \\
0.01 \\
0.02\end{array}$ & $\begin{array}{c}2.46 \\
-0.07 \\
0.05 \\
0.15 \\
-0.03\end{array}$ & $\begin{array}{l}3.6 \\
1.0 \\
2.7\end{array}$ & $\begin{array}{c}<0.0001 \\
0.10 \\
0.35 \\
0.0004 \\
0.57 \\
<0.0001 \\
0.40 \\
0.07\end{array}$ \\
\hline
\end{tabular}

EDF: effective degrees of freedom; s(): penalised regression spline; BMI\%: body mass index percentile; ti(): tensor product interaction; te(l): tensor product smooth. " : for categorical variables; on $\log F_{\mathrm{ENO}_{50}} \mathrm{scale}$; ๆ: EDF for the smooth term; a value of 1 indicates a linear effect, higher values indicate a higher degree of non-linearity; ${ }^{+}$: $k=5$ specified in the slage, by=race, $m=1, k=5$ ) term for improved model convergence.

Analyses stratifying $F_{\mathrm{ENO}_{50}}$ trajectories by age at peak height velocity reduced the sample size to 611 participants due to insufficient height data needed to identify age at peak height velocity; however, sex-specific $F_{\mathrm{ENO}_{50}}$-age trajectories were similar in this subset compared with the full study population (supplementary figure E2). Separation in $F_{\mathrm{ENO}_{50}}$ trajectories between males and females occurred at younger ages among children with early age at peak height velocity and at older ages among children with late age at peak height velocity (figure 4 and supplementary table E5). 
FIGURE 4 Modelled sex-specific trajectory of fractional exhaled nitric oxide $\left(F_{\mathrm{ENO}_{50}}\right)$ ( $\mathrm{n}=288$ males, $\mathrm{n}=323$ females) as a joint smooth of age that vary by early or late age at peak height velocity for males and females. Sex-specific models including a joint smooth of age and year 3 body mass index percentile by category of age at peak height velocity and adjustments for race/ ethnicity and year 3 allergic rhinitis status. Grey bars at bottom present histogram of age.

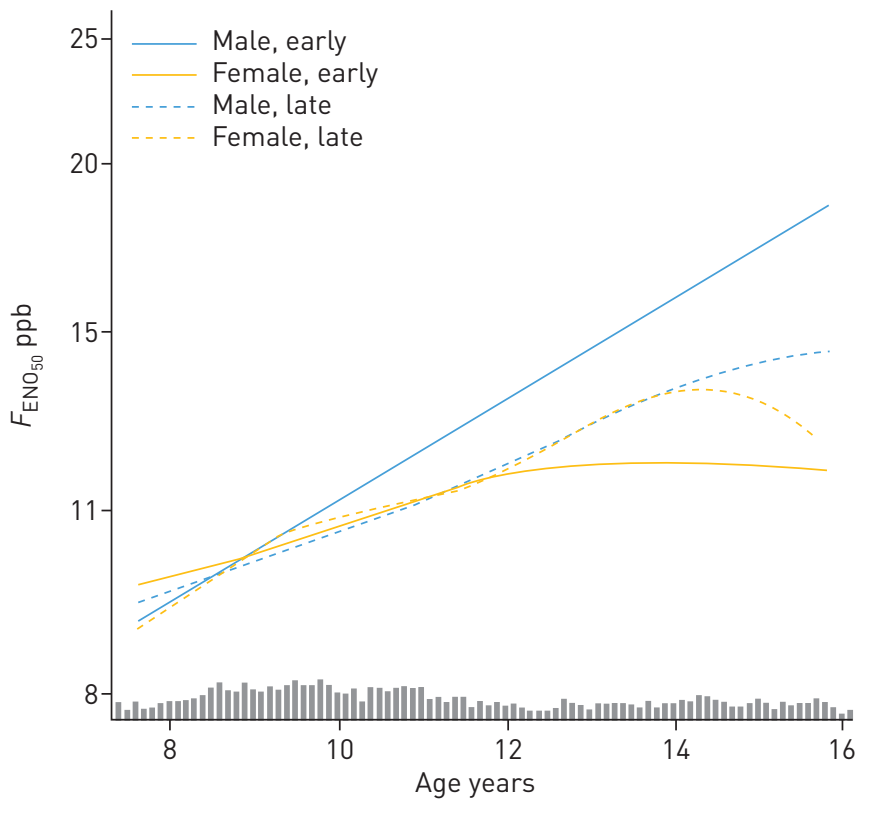

The main findings of diverging $F_{\mathrm{ENO}_{50}}$ trajectories between males and females in later childhood and attenuated $F_{\mathrm{ENO}_{50}}$ trajectory slopes for males with higher year $3 \mathrm{BMI} \%$ were robust in sensitivity analyses (trajectories in height rather than age, supplementary table E6 and supplementary figure E3; trajectories in age using time-varying BMI\% instead of year 3 BMI\%, supplementary figure E4; trajectories in age in children without allergic rhinitis, supplementary figures E5 and E6; trajectories in age in children without wheeze or whistling in the chest, supplementary figures $\mathrm{E} 7$ and $\mathrm{E} 8$; and restricting to online $F_{\mathrm{ENO}_{50}}$ measurements, supplementary figures E9 and E10). Although year 3 BMI\% did not reach statistical significance as a modifier of $F_{\mathrm{ENO}_{50}}$ trajectories when restricting to online $F_{\mathrm{ENO}_{50}}$ measurements, the patterns observed by year $3 \mathrm{BMI} \%$ was similar for the overlapping ages in the two analyses ( $\sim 10$ years to $\sim 16$ years). Additionally, we further excluded $F_{\mathrm{ENO}_{50}}$ observations with reported respiratory infection in the past month and results were not markedly different (data not shown).

\section{Discussion}

Using repeated $F_{\mathrm{ENO}_{50}}$ measurements from a large, population-based sample of healthy children during a period of prepubescent/pubescent growth (median starting age 8.4 years through median age at end of follow-up 15.3 years), we report longitudinal evidence that on average $F_{\mathrm{ENO}_{50}}$ increased nonlinearly with age, with larger increases in males than females at older ages. Interestingly, when stratified by early or late age at peak height velocity, this departure in $F_{\mathrm{ENO}_{50}}$ trajectories between the sexes shifted to younger or older ages coinciding with early/later estimated timing of puberty. Additionally, males with higher year 3 BMI\% had attenuated $F_{\mathrm{ENO}_{50}}$ slopes in age and race/ethnicity in males and year 3 allergic rhinitis in both sexes affected $F_{\mathrm{ENO}_{50}}$ level but did not have impact on $F_{\mathrm{ENO}_{50}}$ trajectories. We also observed considerable unexplained variation in $F_{\mathrm{ENO}_{50}}$ level and $F_{\mathrm{ENO}_{50}}$ change across age between children (large standard deviation of random intercept and slope).

Longitudinal trends in $F_{\mathrm{ENO}_{50}}$ among children as they age observed in this study confirm reports of age association from previous cross-sectional studies in children and adolescents [5, 7, 10, 25]. Combining both sexes, linear increases in $F_{\mathrm{ENO}_{50}}$ were reported by BuCHVALD et al. [7] over ages 4-17 years and YAO et al. [25] over ages 5-18 years, while JACINTO et al. [5] reported linear increases in $F_{\mathrm{ENO}_{50}}$ through 14.1 years old in females and 15.7 years in males, after which point $F_{\mathrm{ENO}_{50}}$ levels plateaued until late middle age. BRODy et al. [10] reported no difference in $F_{\mathrm{ENO}_{50}}$ levels for males and females at ages 611 years, but at ages 12-19 years females had lower $F_{\mathrm{ENO}_{50}}$ levels than males. The $F_{\mathrm{ENO}_{50}}$ levels reported here are slightly larger compared with these earlier studies, but this may be due in part to the large percentage $(69 \%)$ of non-white participants (see discussion later regarding race/ethnicity and $F_{\mathrm{ENO}_{50}}$ ). Overall, these earlier studies are generally consistent with our findings that males and females have similar $F_{\mathrm{ENO}_{50}}$ trajectories until early adolescence, after which males exhibit continued increases while females appear to plateau. Somatic growth and the increase in anatomic dead space volume may be a biological rationale for increases in $F_{\mathrm{ENO}_{50}}$ with age and differences between males and females in later childhood [5]. Development and growth of the bronchial tree leads to larger total airway mucosal surface area available 
for $\mathrm{NO}$ diffusion, thus higher $F_{\mathrm{ENO}_{50}}$ [5]. Potential impacts of alveolar growth on $F_{\mathrm{ENO}_{50}}$ trajectories could be investigated in future studies of alveolar versus airway $\mathrm{NO}$ concentrations $[26,27]$. Although we did not have data on pubertal staging for participants, we were able to use a proxy for puberty (age at peak height velocity) to assign children as either early or late maturers. Timing of divergence between the sexes in $F_{\mathrm{ENO}_{50}}$ trajectories corresponded with this estimate of early versus late onset of puberty. Sex hormones have been suggested by animal studies to be involved in mechanisms of lung inflammation and asthma [28], with ovarian hormones found to increase and testosterone found to decrease airway inflammation in asthma; however, there are discrepancies between experimental and epidemiological studies [14]. The mechanism by which puberty may affect $F_{\mathrm{ENO}_{50}}$ trajectories is unclear, but may shed light on sex differences trends in asthma and other allergic diseases.

With these longitudinal data, we were able to observe differences in $F_{\mathrm{ENO}_{50}}$ slopes by $\mathrm{BMI} \%$ among male children, with participants with higher year $3 \mathrm{BMI} \%$ having attenuated $F_{\mathrm{ENO}_{50}}$ slopes which persisted after controlling for race/ethnicity and year 3 allergic rhinitis. Differences in slope are primarily observed in earlier ages (8-10 years). This pattern was observed both for year 3 BMI\% and time-varying BMI\%. Previous studies have found no association between $F_{\mathrm{ENO}_{50}}$ in children and weight [6-8], body surface area [8] or BMI [7, 10, 29], with exception of a reported negative association with BMI z-score, primarily in atopic children [30] and weak positive correlation for body surface area [7]. BMI\%, which is considered in the present study, may better represent being under-/overweight at a given age and sex. Furthermore, the longitudinal associations we examined (the impact of prepubescent $\mathrm{BMI} \%$ on $F_{\mathrm{ENO}_{50}}$ trajectory during adolescence) may differ from cross-sectional associations. A recent study found individuals with higher BMI to have greater adipose tissue area within airway walls and greater airway wall thickness [31]. This structural change in the airways could potentially impact airway NO production/diffusion as well as $F_{\mathrm{ENO}_{50}}$ measured at the mouth.

In addition, we observed an association between allergic rhinitis and $F_{\mathrm{ENO}_{50}}$, which is supported by the literature $[7,8,32,33]$, although some studies report no association [6]. Some studies of $F_{\mathrm{ENO}_{50}}$ in healthy children exclude those with reported rhinitis [33], but results were similar in our sensitivity analyses excluding children with allergic rhinitis.

Non-Hispanic white males had lower $F_{\mathrm{ENO}_{50}}$ levels across age compared with Hispanic males and males from all other races. Similar patterns were observed for females, but results did not reach statistical significance. Evidence from cross-sectional studies supports an association between race/ethnicity and $F_{\mathrm{ENO}_{50}}$. A 2017 review reported that among eight studies with children, seven found race/ethnicity to be a significant influencing factor for $F_{\mathrm{ENO}_{50}}$, with six observing higher $F_{\mathrm{ENO}_{50}}$ levels in the non-Caucasian ethnic groups (including African American, Hispanic and Asian) compared with Caucasian levels [34]. Higher $F_{\mathrm{ENO}_{50}}$ has been reported in non-Hispanic black and Hispanic children compared to non-Hispanic white children aged 6-19 years in the United States [10]. In a separate study, non-Caucasian subjects (African American, Asian, and Hispanic subjects) had higher $F_{\mathrm{ENO}_{50}}$ compared with Caucasian subjects, but this difference was only borderline significant after controlling for age, sex and self-reported atopy [7]. Whether differences are driven by genetic versus contextual factors is unclear and warrants further investigation.

This study has limitations. First, the age range is limited, thus it is unclear whether differences between males and females persist into early adulthood. Second, due to budgetary constraints $F_{\mathrm{ENO}_{50}}$ assessments were conducted every 2 years in years 6-10; however, because there was a range of ages at study entry, inference regarding $F_{\mathrm{ENO}_{50}}$ trajectory in early and mid-teenage years are well supported by the data. Third, the first 2 years of $F_{\mathrm{ENO}_{50}}$ data (years 3 and 4) were collected using offline methods, while $F_{\mathrm{ENO}_{50}}$ data for the remainder of the study (years 5-10) were collected using online methods. Although offline $F_{\mathrm{ENO}_{50}}$ measurement were converted to online values based on a published internally developed prediction model with an $\mathrm{R}^{2}=0.94$ [17], there remains a possibility that this change in breath collection technique during the study could influence $F_{\mathrm{ENO}_{50}}$ trajectories in age, especially for estimated trajectories around ages 9-10 years when the change in collection method occurred which coincides with an apparent attenuation in $F_{\mathrm{ENO}_{50}}$ slope. However, in sensitivity analyses restricted to online $F_{\mathrm{ENO}_{50}}$ measurements, patterns in $F_{\mathrm{ENO}_{50}}$ trajectories, including the divergence between the sexes in later childhood, were similar to those in the main analysis, although the attenuation in slope around ages 9-11 years was less evident and remained only for males. The only other difference was in the findings for year $3 \mathrm{BMI} \%$, which is likely due to lack of data in younger ages: the age period when $F_{\mathrm{ENO}_{50}}$ slope was most different by BMI\% in the main analysis. Fourth, guidelines have been updated after the conclusion of data collection, but these would not have substantively impacted our $F_{\mathrm{ENO}_{50}}$ collection protocol [35]. Last, an objective measure of atopy (e.g. skin prick test, IgE sensitisation) was not available and we instead relied on questionnaire assessment of allergic rhinitis. IgE sensitisation may be present without obvious symptoms and may still cause increased $F_{\mathrm{ENO}_{50}}$, but would not have been captured by our classification of allergic rhinitis. Without such data we were unable to investigate the potential for effect modification by atopy. 
This study has several strengths. First, we leveraged a large unique longitudinal data resource to be the first study to use serial measurements to examine $F_{\mathrm{ENO}_{50}}$ age trajectories in healthy children. Second, $F_{\mathrm{ENO}_{50}}$ trajectories are investigated during an important period of growth for children. Last, the study population is diverse, with $>50 \%$ Hispanic participants, allowing for identification of racial/ethnic differences in $F_{\mathrm{ENO}_{50}}$-age trajectories.

In conclusion, we reported novel longitudinal evidence for nonlinear trajectories of $F_{\mathrm{ENO}_{50}}$ in healthy children followed from ages $\sim 8$ to $\sim 15$ years, with differences in trajectories by sex coinciding with puberty and prepubescent $\mathrm{BMI} \%$, and differences in level by allergic rhinitis and race/ethnicity. The considerable remaining unexplained between-child variability in trajectories highlights the limitations of fixed $F_{\mathrm{ENO}_{50}}$ reference values. As such, our results are not intended as reference growth curves, but to provide information on population average $F_{\mathrm{ENO}_{50}}$ trajectories in healthy children during a period of growth. However, the moderately strong within-participant correlation of $F_{\mathrm{ENO}_{50}}$ over an 8-year period suggests that tracking personalised $F_{\mathrm{ENO}_{50}}$ measurements over time (to exploit this high within-participant correlation) may maximise the clinical utility of $F_{\mathrm{ENO}_{50}}$ measurements [36, 37].

Acknowledgements: We thank the participating students and their families, the school staff and administrators and the study field team for their efforts.

Conflict of interest: E. Garcia has nothing to disclose. Y. Zhang reports grants from NIH, AHRQ, VA and CDC, outside the submitted work. E.B. Rappaport has nothing to disclose. K. Berhane reports grants from NIH, during the conduct of the study. P. Muchmore reports grants from National Institute of Environmental Health Sciences, USA (grant number T32ES013678), during the conduct of the study; and has a patent PCT/US2018/042316 pending. P.E. Silkoff has nothing to disclose. N. Molshatzki has nothing to disclose. F.D. Gilliland has nothing to disclose. S.P. Eckel reports grants from NIH, during the conduct of the study.

Support statement: This work was supported by the National Heart, Lung, and Blood Institute (grants R01HL61768 and R01HL76647); the Southern California Environmental Health Sciences Center (grant P30ES007048) funded by the National Institute of Environmental Health Sciences; the Children's Environmental Health Center (grants P01ES009581, R826708-01 and RD831861-01) funded by the National Institute of Environmental Health Sciences and the Environmental Protection Agency; the National Institute of Environmental Health Sciences (grants P01ES011627, R01ES023262, R01ES027860, and T32ES013678); the James H. Zumberge Research and Innovation Fund, and the Hastings Foundation. Funding information for this article has been deposited with the Crossref Funder Registry.

\section{References}

1 Berry MA, Shaw DE, Green RH, et al. The use of exhaled nitric oxide concentration to identify eosinophilic airway inflammation: an observational study in adults with asthma. Clin Exp Allergy 2005; 35: 1175-1179.

2 Mahr TA, Malka J, Spahn JD. Inflammometry in pediatric asthma: a review of fractional exhaled nitric oxide in clinical practice. Allergy Asthma Proc 2013; 34: 210-219.

3 Dweik RA, Boggs PB, Erzurum SC, et al. An official ATS clinical practice guideline: interpretation of exhaled nitric oxide levels $\left(F_{\mathrm{ENO}}\right)$ for clinical applications. Am J Respir Crit Care Med 2011; 184: 602-615.

4 American Thoracic Society, European Respiratory Society. ATS/ERS recommendations for standardized procedures for the online and offline measurement of exhaled lower respiratory nitric oxide and nasal nitric oxide, 2005. Am J Respir Crit Care Med 2005; 171: 912-930.

5 Jacinto T, Malinovschi A, Janson C, et al. Evolution of exhaled nitric oxide levels throughout development and aging of healthy humans. J Breath Res 2015; 9: 036005.

6 Mallol J, Aguirre V, Córdova P, et al. Fraction of exhaled nitric oxide in healthy Chilean schoolchildren aged 8-15 years. Allergol Immunopathol 2015; 43: 528-532.

7 Buchvald F, Baraldi E, Carraro S, et al. Measurements of exhaled nitric oxide in healthy subjects age 4 to 17 years. J Allergy Clin Immunol 2005; 115: 1130-1136.

8 Malmberg LP, Petäys T, Haahtela T, et al. Exhaled nitric oxide in healthy nonatopic school-age children: determinants and height-adjusted reference values. Pediatr Pulmonol 2006; 41: 635-642.

9 Rouatbi S, Alqodwa A, Ben Mdella S, et al. Fraction of exhaled nitric oxide $\left(F_{\mathrm{eNO}}\right)$ norms in healthy North African children 5-16 years old. Pediatr Pulmonol 2013; 48: 981-995.

10 Brody DJ, Zhang X, Kit BK, et al. Reference values and factors associated with exhaled nitric oxide: U.S. youth and adults. Respir Med 2013; 107: 1682-1691.

11 Högman M, Thornadtsson A, Liv P, et al. Effects of growth and aging on the reference values of pulmonary nitric oxide dynamics in healthy subjects. J Breath Res 2017; 11: 047103.

12 Almqvist C, Worm M, Leynaert B, et al. Impact of gender on asthma in childhood and adolescence: a GA2LEN review. Allergy 2008; 63: 47-57.

13 Pinart M, Keller T, Reich A, et al. Sex-related allergic rhinitis prevalence switch from childhood to adulthood: a systematic review and meta-analysis. Int Arch Allergy Immunol 2017; 172: 224-235.

14 Naeem A, Silveyra P. Sex differences in paediatric and adult asthma. Eur Med J 2019; 4: 27-35.

15 McConnell R, Berhane K, Yao L, et al. Traffic, susceptibility, and childhood asthma. Environ Health Perspect 2006; 114: 766-772.

16 Bastain TM, Islam T, Berhane KT, et al. Exhaled nitric oxide, susceptibility and new-onset asthma in the Children's Health Study. Eur Respir J 2011; 37: 523-531.

17 Linn WS, Berhane KT, Rappaport EB, et al. Relationships of online exhaled, offline exhaled, and ambient nitric oxide in an epidemiologic survey of schoolchildren. J Expo Sci Environ Epidemiol 2009; 19: 674-681.

18 Linn WS, Rappaport EB, Berhane KT, et al. Exhaled nitric oxide in a population-based study of southern California schoolchildren. Respir Res 2009; 10: 28. 
19 American Thoracic Society. Recommendations for standardized procedures for the on-line and off-line measurement of exhaled lower respiratory nitric oxide and nasal nitric oxide in adults and children - 1999. This official statement of the American Thoracic Society was adopted by the ATS Board of Directors, July 1999. Am J Respir Crit Care Med 1999; 160: 2104-2117.

20 Kuczmarski RJ, Ogden CL, Guo SS, et al. 2000 CDC Growth Charts for the United States: methods and development. Vital Health Stat 11 2002; 246: 1-190.

21 Kelly A, Winer KK, Kalkwarf H, et al. Age-based reference ranges for annual height velocity in US children. J Clin Endocrinol Metab 2014; 99: 2104-2112.

22 Wood SN. Stable and efficient multiple smoothing parameter estimation for generalized additive models. $J$ Am Stat Assoc 2004; 99: 673-686.

23 Wood SN. Generalized Additive Models: an Introduction with R. Boca Raton, CRC Press, 2017.

24 R Core Team. R: A Language and Environment for Statistical Computing. Vienna, R Foundation for Statistical Computing, 2018.

25 Yao TC, Lee WI, Ou LS, et al. Reference values of exhaled nitric oxide in healthy Asian children aged 5 to 18 years. Eur Respir J 2012; 39: 378-384.

26 George SC, Hogman M, Permutt S, et al. Modeling pulmonary nitric oxide exchange. J Appl Physiol 2004; 96: 831-839.

27 Högman M. Extended NO analysis in health and disease. J Breath Res 2012; 6: 047103.

28 Yung JA, Fuseini H, Newcomb DC. Hormones, sex, and asthma. Ann Allergy Asthma Immunol 2018; 120: 488-494.

29 Kovesi T, Kulka R, Dales R. Exhaled nitric oxide concentration is affected by age, height, and race in healthy 9- to 12-year-old children. Chest 2008; 133: 169-175.

30 Yao TC, Tsai HJ, Chang SW, et al. Obesity disproportionately impacts lung volumes, airflow and exhaled nitric oxide in children. PLoS One 2017; 12: e0174691.

31 Elliot JG, Donovan GM, Wang KCW, et al. Fatty airways: implications for obstructive disease. Eur Respir J 2019; 54: 1900857.

32 Jouaville LF, Annesi-Maesano I, Nguyen LT, et al. Interrelationships among asthma, atopy, rhinitis and exhaled nitric oxide in a population-based sample of children. Clin Exp Allergy 2003; 33: 1506-1511.

33 Jacinto T, Alving K, Correia R, et al. Setting reference values for exhaled nitric oxide: a systematic review. Clin Respir J 2013; 7: 113-120.

34 Blake TL, Chang $\mathrm{AB}$, Chatfield MD, et al. Does ethnicity influence fractional exhaled nitric oxide in healthy individuals?: a systematic review. Chest 2017; 152: 40-50.

35 Horváth I, Barnes PJ, Loukides S, et al. A European Respiratory Society technical standard: exhaled biomarkers in lung disease. Eur Respir J 2017; 49: 1600965.

36 Ferrante G, Malizia V, Antona R, et al. The value of $F_{\mathrm{eNO}}$ measurement in childhood asthma: uncertainties and perspectives. Multidiscip Respir Med 2013; 8: 50.

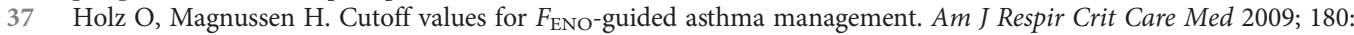
$281-282$. 